\section{Burial Terminology: A Guide for Researchers}

\section{AltaMira Press, Lanham, MD, 2005. 288 pp., 33 figs., 8 tables, refs., index. \$34.95 paper.}

\section{Roderick Sprague}

As evidenced by the sheer number of works referenced in this book, the need for a consistent system of burial nomenclature is readily apparent. Burial Terminology presents a comprehensive guide for use by researchers when describing human burials archaeologically encountered. Roderick Sprague's objective is the establishment of terminology that is consistent across disciplines to allow for easier description of burial and disposal practices. The focus is placed on what Sprague terms "disposal of the dead" (p. 2), rather than the mortuary/funerary activities preceding what is represented archaeologically. Sprague, with research interests in funerary and historical archaeology, is no stranger to the issues faced when encountering human burials.

The introduction includes a brief overview of terminology previously used to describe mortuary activities. Sprague notes that this work pulls together vocabulary used by prehistorians, historical archaeologists, forensic anthropologists, and ethnographers from North America, Western Europe, Australia, and Asia (p. 6). Chapter 2 provides an historical background of burial terminology through a discussion of publications produced over the past several hundred years. It is effective in illustrating the abundant number of studies that have been produced. Sprague is not the first to call for a consistent system of burial nomenclature. The historical background is useful in supporting the notion that a classificatory system needs to exhibit categories that are "mutually exclusive and all inclusive" (p. 18).

Chapter 3 presents the field guide, composed of 12 sections accompanied by relevant terminology for use when describing burials, including form of disposal, body preparation, individuality, articulation, position, deposition, orientation and alignment, grave goods, disposal container, features, description of disposal area, and demography (pp. 28-36). Tables list the suggested terms to be used and those that should be avoided when describing burials. This is helpful in providing readers with an organized list of terms discussed in chapter 4. Sprague clarifies that suggested terms are by no means the final word on what should and should not be used for burial descriptions and notes that there is much room for local variation and continual modification. Two supplemental sections, excavation data and data recording, provide suggestions for the proper use of terminology in the field and an excavation checklist to ensure the collection of all relevant data. Chapter 4 provides an in-depth discussion of Sprague's favored burial terminology as well as terms that should be avoided for each of the above-mentioned sections. Where applicable, the discussion includes the context from which both ideal and less-applicable terminology is used in research literature.

Well researched and written, Burial Terminology is extremely useful for researchers dealing with human burials, whether in a prehistoric, historic, ethnographic, or forensic context. Illustrations are useful in conveying sometimes confusing terminology. Perhaps one of the most valuable sections of the book is the extensive reference section. Since obvious space constraints hinder the complete discussion of some sources of terminology or typological systems mentioned, the reference section makes it possible for scholars to locate the sources for additional information. As Sprague notes, "it has been suggested that [a consistent system of burial terminology] is an impossible task, but we shall never know unless we try it" (p. 25). Consequently, this work is successful in providing an extensive reference list and a basic framework from which to build a consistent burial terminology for researchers.

JAMES G. PARKer

DEPARTMENT OF ANTHROPOLOGY

EAST CAROLINA UNIVERSITY

GrEENVILLE, NC 27858-4353

iiiparker@yahoo.com 